\title{
A Case of Mumps Presenting as Severe Pneumonia with Acute Respiratory Distress Syndrome
}

\author{
Neeraj Sharma, Aditya Joshi', Krishna Kumar M1', Neelabh Nayan² \\ Departments of Respiratory Medicine, ${ }^{1}$ Anaesthesiology and Critical Care and ${ }^{2}$ Internal Medicine, Command Hospital, Kolkata, West Bengal, India
}

\section{Abstract}

The mumps virus causes an acute viral syndrome which is generally a self-limiting condition. It primarily affects the children. The majority of cases present with parotid swelling which is usually followed by complete recovery. Symptomatic infection is typically more severe in adults than in children. Encephalitis, meningitis, and orchitis are the most common serious complications of mumps. Pneumonia is an extremely rare and unusual complication of mumps. In this case report, the patient was an adult who presented with a short history of fever, unilateral parotid swelling, cough, and worsening breathlessness. On evaluation, he was diagnosed as a case of mumps complicated with severe pneumonia. The patient later developed a severe acute respiratory distress syndrome, which was managed successfully by prone ventilation, recruitment maneuvers, lung-protective ventilation (high positive end-expiratory pressure and low tidal volume), and other supportive measures.

Keywords: Acute respiratory distress syndrome, lung-protective ventilation, mumps, pneumonia, prone ventilation

\section{INTRODUCTION}

The mumps virus causes an acute viral syndrome that is usually self-limiting. Mumps occurred mainly in young children attending primary school before the widespread use of an effective vaccine. ${ }^{[1]}$ It is a highly contagious disease, which is transmitted by respiratory droplets, fomites, and direct contact. ${ }^{[2]}$ Mumps virus infection primarily involves the parotid glands. In the outpatient setting, the diagnosis is readily apparent by clinical inspection and palpation of the enlarged parotid gland. Laboratory investigations are not routinely required. There is no specific therapy for mumps, and the treatment is entirely symptomatic. The affected patient generally retains lifelong immunity. Mumps is rarely encountered in adults, as most of the children have been vaccinated within the first 2 years of life. Extra-parotid manifestations in mumps are rare and present with a diagnostic challenge. The most common serious complications of mumps are orchitis, meningitis, and encephalitis. Pneumonia is a rare and unusual complication of mumps. We describe an unusual case of mumps in an adult patient presenting with unilateral parotid swelling and severe pneumonia progressing to acute respiratory distress syndrome (ARDS).

\begin{tabular}{|l|l|}
\hline \multicolumn{2}{|c|}{ Access this article online } \\
\hline Quick Response Code: & Website: \\
& www.ijrconline.org \\
\cline { 2 - 3 } & \\
& \\
\end{tabular}

\section{Case Report}

A 25-year-old male with no known comorbidities was admitted to the hospital with complaints of fever, generalized weakness, left-sided facial swelling, dry cough, and breathlessness of 5 days' duration. Fever was continuous in nature with a maximum recorded temperature of $103^{\circ} \mathrm{F}$ and was associated with chills and generalized weakness. It was followed by dry cough and progressive breathlessness, which worsened from Modified medical research council grade 1 to 4 (MMRC Grade 1-4) over 5 days. On admission, he was febrile, had tachypnea, tachycardia, and was not maintaining oxygen saturation on room air. He was found to have unilateral parotid swelling over the left side [Figure 1]. Respiratory examination revealed the use of accessory muscles of respiration and diffuse bilateral inspiratory crackles on auscultation. Laboratory investigations showed leukopenia (total leukocyte count: $2800 / \mu \mathrm{L}$ ), transaminitis,

Address for correspondence: Dr. Neeraj Sharma, Department of Respiratory Medicine, Command Hospital, Eastern Command, Alipore, Near Visa House, Kolkata - 700 027, West Bengal, India. E-mail: dmt18sharma@gmail.com

This is an open access journal, and articles are distributed under the terms of the Creative Commons Attribution-NonCommercial-ShareAlike 4.0 License, which allows others to remix, tweak, and build upon the work non-commercially, as long as appropriate credit is given and the new creations are licensed under the identical terms.

For reprints contact: reprints@medknow.com

How to cite this article: Sharma N, Joshi A, Kumar MK, Nayan N. A case of mumps presenting as severe pneumonia with acute respiratory distress syndrome. Indian J Respir Care 2020;9:227-9.

Received: 20-10-2019 Revised: 21-10-2019 Accepted: 29-11-2019

Published: 19-06-2020 
and raised lactate dehydrogenase levels (1300 U/L). Arterial blood gas $(\mathrm{ABG})$ revealed hypoxemia $\left(\mathrm{PaO}_{2} / \mathrm{FiO}_{2}\right.$ : $<200)$. Chest radiograph [Figure 2] showed bilateral fluffy opacities (left $>$ right). His two-dimensional echo and serum brain natriuretic peptide levels were normal. He was initially being diagnosed as a case of atypical pneumonia with ARDS. He was managed with parenteral antibiotics, tablet doxycycline, tablet oseltamivir, oxygen therapy, noninvasive ventilation (NIV), and other supportive therapy. He was subjected to computed tomography chest [Figure 3], which revealed extensive ground-glass opacities in bilateral lung fields with peripheral sparing. He showed a poor response to the therapy and was later intubated in view of worsening $\mathrm{PaO}_{2} / \mathrm{FiO}_{2}$ ratio in subsequent $\mathrm{ABG}$ (analysis) despite NIV therapy. He was intubated and invasively ventilated using ventilation strategy as per the ARDS net protocol with lung-protective ventilation (low tidal volume ventilation with high positive end-expiratory pressure [PEEP]). He was paralyzed in view of the patient-ventilator asynchrony and was put on prone ventilation for initial $16 \mathrm{~h}$. Recruitment maneuvers were also carried out intermittently during mechanical ventilation. His subsequent $\mathrm{ABG}$ showed improvement in oxygenation $\left(\mathrm{PaO}_{2} / \mathrm{FiO}_{2}>200\right)$ and regression of opacities on the chest radiograph [Figure 4]. He developed pressure necrosis of the skin over the left side of chin as a consequence of the prone ventilation [Figure 1]. His investigations showed dengue serology and peripheral blood smear for malaria parasite (both negative), endotracheal tube secretions for H1N1 reverse transcription polymerase chain reaction (negative), Weil-Felix test (negative), ultrasound of the neck and parotid region showed an enlarged parotid and submandibular gland on the left side, and mumps virus antibody panel (both immunoglobulin IgM and IgG @ enzyme immunoassay) was positive. The presence of parotid gland swelling, positive mumps virus antibody panel (both $\operatorname{IgG}$ and $\operatorname{IgM}$ ) and ruling out other febrile illnesses confirmed the diagnosis of mumps. He was diagnosed as a case of mumps with severe pneumonia progressing to ARDS. The patient responded well to the ventilation strategy and was extubated after 4 days of

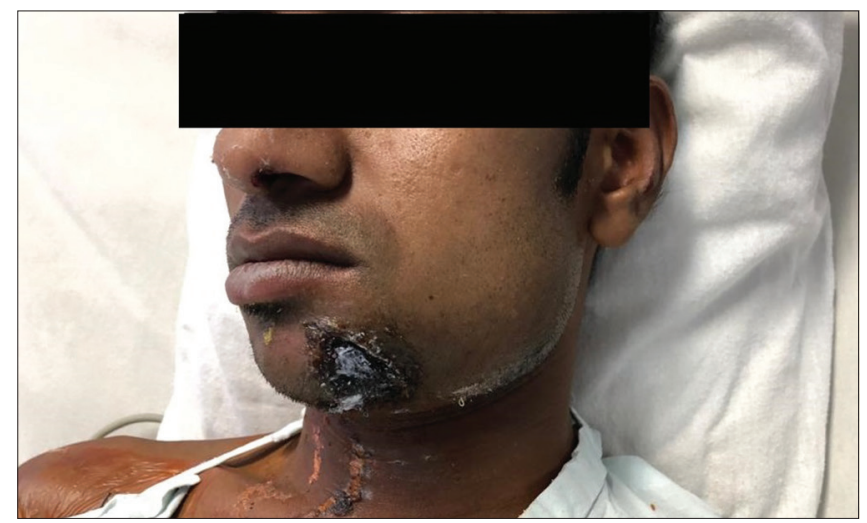

Figure 1: Patient had unilateral parotid swelling on the left side. He developed pressure necrosis of skin over the left side of chin as a consequence of prone ventilation mechanical ventilation. His left-sided parotid swelling also improved during the hospital stay and he was later discharged. He denied a history of mumps parotitis in the childhood.

\section{Discussion}

The mumps virus belongs to the genus Rubulavirus in the paramyxoviridae family. It is an enveloped virus containing a nonsegmented single-stranded RNA. Human beings are the only natural mumps virus host. It is a highly contagious infection that is transmitted by inhalation route or oral contact with contaminated respiratory droplets or secretions. The virus proliferates in the upper respiratory tract epithelium during the incubation period, which is about 2-4 weeks. Transient plasma viremia results in the dissemination of viruses into organs $^{[3]}$ (parotid glands, central nervous system, pancreas, urinary tract, and genital organs). Infection with mumps is usually accompanied by a nonspecific viral prodrome of malaise, nausea, low-grade fever, and anorexia. ${ }^{[4]}$ Parotitis, leading to parotid enlargement, follows these symptoms in $48 \mathrm{~h}$. Parotitis is due to local inflammation and direct infection of the ductal epithelium by the virus. The majority of patients present with parotid swelling which is usually bilateral. It subsides within a few weeks of symptom onset. Unlike this classic presentation, asymptomatic disease occurs in 15\%-20\% of cases, and predominantly respiratory symptoms with other nonspecific features are seen in up to $50 \%$ of cases, in whom the diagnosis of mumps is not usually made. ${ }^{[5]}$

Symptomatic infection is more severe in adults as compared to children. Meningitis, encephalitis, and orchitis are the most common serious complications of mumps. These complications can sometimes occur in the absence of parotitis and can hinder the correct diagnosis. ${ }^{[6]}$ The diagnosis of mumps is based on the typical clinical symptoms, that is, viral prodrome followed by parotid enlargement and regular blood test, indicating leukopenia with relative lymphocytosis and elevated serum amylase levels. However, laboratory testing is essential for complicated cases of mumps, or if infection occurs

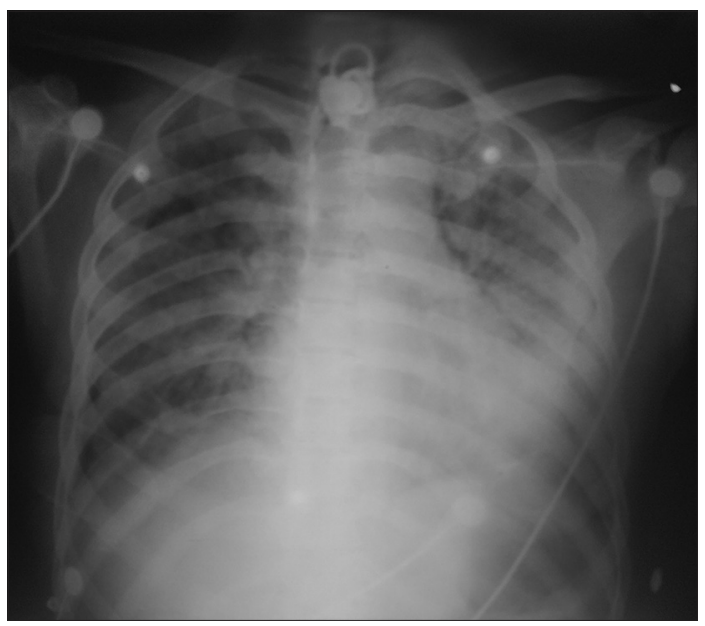

Figure 2: Bilateral fluffy opacities on the chest radiograph 
Sharma, et al:: A case of mumps presenting as severe pneumonia with acute respiratory distress syndrome

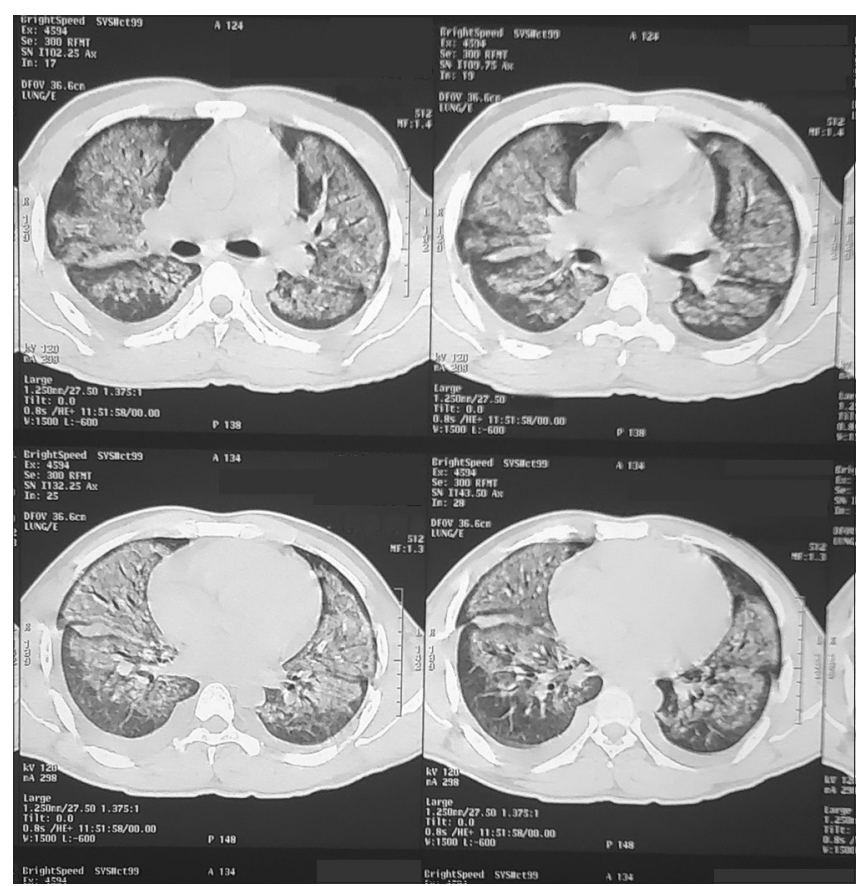

Figure 3: Computed tomography chest of the patient showing bilateral ground-glass opacities

after vaccination. Serological methods ${ }^{[7]}$ (seroconversion or a four-fold increase in the antibody titres or detection of virus-specific IgM antibody 7-10 days after symptom onset) classically confirm the diagnosis of mumps infection. The diagnostic specificity is $87.5 \%$, the sensitivity is $>95 \%$ for the $\mathrm{IgG}$ test, and the diagnostic specificity and sensitivity are $>95 \%$ for the IgM test used. ${ }^{[8]}$

At present, there is no specific antiviral therapy for mumps. The treatment is mostly symptomatic and supportive, as it is a generally benign and self-resolving illness. Pneumonia as a complication of mumps infection is very rare. Our case was diagnosed as a case of mumps based on the presence of parotid gland swelling, positive mumps virus antibody panel (both IgG and IgM), and ruling out other causes of febrile illness. The patient developed pneumonia with severe ARDS during hospital stay, which was managed by prone ventilation, recruitment maneuvers, and lung-protective ventilation (high PEEP and low tidal volume). The patient responded well to the ventilator strategy and was extubated after 4 days of mechanical ventilation. His left-sided parotid swelling also improved during hospital stay and he was later discharged.

\section{Conclusion}

The mumps virus causes an acute viral illness that primarily affects children and is usually a self-limiting condition. Parotid enlargement associated with viral prodrome is the most common presentation. In general, symptomatic infection is more severe in adults than in children. At present, there is no specific antiviral therapy for mumps. The treatment is mostly symptomatic and supportive, as it is a benign and

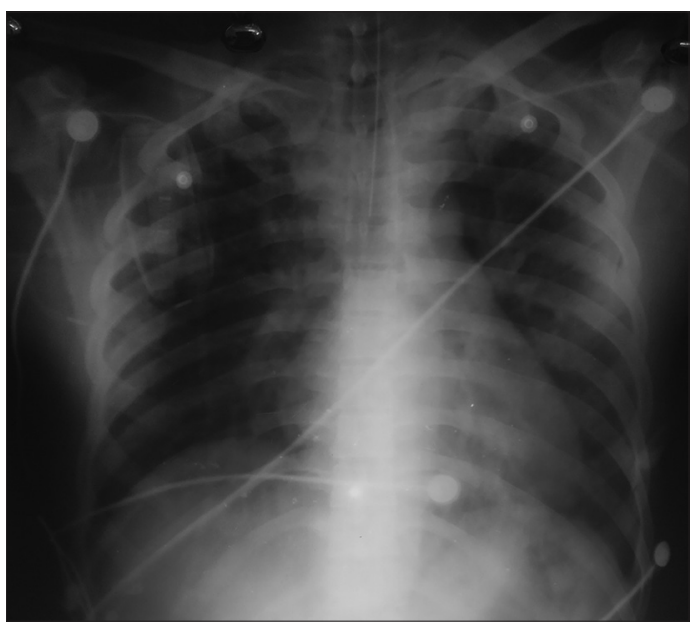

Figure 4: A chest radiograph improved with the therapy

self-resolving illness. Pneumonia is a very rare and unusual complication of mumps and can sometimes progress to ARDS. The management of viral pneumonia progressing to ARDS is primarily supportive in the form of lung-protective ventilation and prevention of complications associated with mechanical ventilation.

\section{Declaration of patient consent}

The authors certify that they have obtained all appropriate patient consent forms. In the form the patient has given his consent for his images and other clinical information to be reported in the journal. The patient understands that his names and initials will not be published and due efforts will be made to conceal his identity, but anonymity cannot be guaranteed.

\section{Financial support and sponsorship}

Nil.

\section{Conflicts of interest}

There are no conflicts of interest.

\section{References}

1. Dayan GH, Rubin S. Mumps outbreaks in vaccinated populations: Are available mumps vaccines effective enough to prevent outbreaks? Clin Infect Dis 2008;47:1458-67.

2. Gupta RK, Best J, MacMahon E. Mumps and the UK epidemic 2005. BMJ 2005;330:1132-5.

3. Hviid A, Rubin S, Mühlemann K. Mumps. Lancet 2008;371:932-44.

4. Wharton M, Cochi SL, Williams WW. Measles, mumps, and rubella vaccines. Infect Dis Clin North Am 1990;4:47-73.

5. Foy HM, Cooney MK, Hall CE, Bor E, Maletzky AJ. Isolation of mumps virus from children with acute lower respiratory tract disease. Am J Epidemiol 1971;94:467-72.

6. Wharton M, Cochi SL, Hutcheson RH, Bistowish JM, Schaffner W. A large outbreak of mumps in the postvaccine era. J Infect Dis 1988;158:1253-60.

7. Rubin S, Plotkin S. Mumps. In: Vaccines. $6^{\text {th }}$ ed. Philadelphia: Saunders; 2013. p. 419-46.

8. Available from: http://www.novatecid.com/fileadmin/user_upload/ Product_Insert/MUMG0340eng1__dt_fr_it_es10082009.pdf. [Last accessed on 2019 Oct 15]. 